\title{
Pyrolysis Process of Mixed Polypropylene (PP) and High-Density Polyethylene (HDPE) Waste with Natural Zeolite as Catalyst
}

\author{
Emi Erawati ${ }^{*}$, Hamid $^{1}$, Annisa Ayu Ima ${ }^{1}$ \\ ${ }^{1}$ Chemical Engineering Department, Engineering Faculty, Universitas Muhammadiyah Surakarta, Indonesia \\ *email: emi.erawati@ums.ac.id
}

Received November 7, 2017; Accepted March 21, 2018; Available online December 8, 2018

\begin{abstract}
The reactor of the experiment was made from stainless steel with the diameter of $25 \mathrm{~cm}$ and the height of 30 $\mathrm{cm}$. The liquid petroleum gas was used as a fuel in the reactor. The reactor was connected by the thermocouple that controls temperature variations at $410,420,430$, and $450^{\circ} \mathrm{C}$. Raw material contained plastic bottles and waste caps, while the natural zeolite as a catalyst was dried and cut in dimensions of $3 \times 3$ $\mathrm{cm}$. A gas as the reacted product was condensed using the first condenser, then the liquid product was collected. Uncondensed gas was condensed again in the second condenser, then the liquid product was collected again. The volume of gas was calculated based on the water volume coming out of the gallon. This was repeated with varied ratios of plastics to natural zeolite $(67: 33 ; 75: 25 ; 80: 20$; and 83:17 wt\%). Pyrolysis was run for two hours and every 20 minutes the sample was weighed to gauge the change in mass of gas and liquid. After 120 minutes, the solid sample was examined to identify the mass of final solid. Based on the research, at the temperature of $440^{\circ} \mathrm{C}$, the highest liquid yield was $68.42 \%$. On the other hand, with the ratio of raw material to zeolite at $83: 17 \mathrm{wt} \%$, the largest yield of liquid was $87.31 \%$. The liquid product in various temperature and comparisons of percentage of raw material to catalyst was found to meet diesel specifications based on The Decree of Director General of Fuels and Gas Year 200,8 Number 14,496 $\mathrm{K} / 14 / \mathrm{DJM} / 2,008$.
\end{abstract}

Keywords: high-density polyethylene, polypropylene, pyrolysis, diesel-fuel

\section{INTRODUCTION}

Plastic has played a vital role in enhancing the living standards of human beings for more than 50 years. It is a key innovation used in many products from various sectors such as construction, healthcare, electronic, automobile, packing, and others. The demand for commodity plastics has increased due to the rapid growth of population. The global production of plastics reached about 299 million tons in 2013 and increased by $4 \%$ over 2012. The continuous rise of plastic demand leads to growing in waste accumulation per day. A statistic from 2013 reported that 33 million tons of plastic were generated in the US. In Europe, 25 million tons of plastic ended up in waste streams during the year of 2012. Statistics also established that in Europe about $38 \%$ of plastic waste went to landfills, $26 \%$ were recycled, and $36 \%$ was utilized for energy recovery. This shows that the percentage of plastic ended up in the landfills is still considerably high, thus occupying a huge space. Plastics may take up to billions of years to degrade naturally. They degrade gradually since the molecular bond containing hydrogen, carbon, and few other components such as nitrogen, chlorine, and others make plastics highly durable. The continuous disposal of plastic in landfills would definitively cause a serious environmental problem (Sharuddin, Abnisa, Daud, \& Aroua, 2016).

There are four main approaches to recycling plastic wastes, which are primary, secondary, tertiary, and quaternary recycling. In primary recycling, product converted from waste plastics have a performance level comparable to that of original product made from virgin plastics. The recycling is very simple without any precaution except for the proper and clean collection of waste in the plant.

In secondary recycling, the product of plastics was conversion have less demanding performance requirement than original material. There are two main approaches to secondary recycling: One approach is to separate the plastics from their contaminant and then segregate the plastics into generic types, one or more of which are then recycled into products from virgin or primary recycled material. The other approach is to separate the plastics from their associated contaminants and re-melt them as a mixture without segregation. The treatment of plastics in a 
waste stream may include a series of material recycling methods, such as size reduction by granulators, shredder or crumbles, and separation of plastics, from other waste material and from one another,

In tertiary recycling, solid plastics are converted into smaller molecules as chemical intermediates by the use of heat and or chemical treatment. These chemical intermediates, usually liquids or gases but sometimes waxes, are suitable for the use as feedstocks for production of new petrochemicals and plastics (Kumar \& Singh, 2011; Roozbehani, Motevassel, Mirdrikvand, Moqadam, \& Kharaghani, 2017)

Quartenary recycling involves the recovery of the energy content of the plastic waste. The owing to the lack of other recycling possibilities, incineration (combustion) aimed at the recovery of energy is currently the most effective way to reduce the volume of organic material.

An alternative thermal approach for dealing with waste plastic is the so-called chemical feedstock or chemical recycling. This term has been used to describe a diversity of techniques including pyrolysis, hydrolysis, hydrogenation, methanolysis, and gasification. The most attractive technique of chemical stock is pyrolysis. Thermal cracking or pyrolysis involves the degradation of the polymeric material absence of oxygen. Unlike mechanical recycling technique in which the long polymeric chains of the plastics are preserved intact, pyrolysis produces smaller molecular weight fragments. The process is usually conducted at temperatures between 500 and $800^{\circ} \mathrm{C}$ and results in the formation of carbonized char and a volatile fraction that may be separated into condensable hydrocarbon oil and non-condensable high calorific value (Kumar \& Singh, 2011).

Several authors have studied pyrolysis of polymers such as the mixed between polyethylene (PE) and polypropylene (PP) (Sakaki, Roozbehani, Shishesaz, \& Abdollahkhani, 2014), mixed polymers containing different concentrations of low density polyethylene (LDPE), HDPE, and PP, (Roozbehani, Sakaki, Shishesaz, Abdollahkhani, \& Hamedifar, 2015), polystyrene (Moqadam, Mirdrikvand, Roozbehani, Kharaghani, \& Shishehsaz, 2015), high density polyethylene (Levine \& Broadbelt, 2009), polyolefins wastes (Mastellone \&
Arena, 2002), polypropylene (Gogotov \& Barazov, 2014; Chen et al., 2007; Åkesson et al., 2013; Kumar \& Singh, 2014), mixed between high density polyethylene and rubber seed shell (Chin et al., 2014), mixed between PE and PP (Aboulkas et al., 2010), mixed between olive residue with HDPE, (LDPE), (PP), and PS (Aboulkas et al., 2009), municipal plastic waste (MPW) consisting of a mixture of thermoplastics (HDPE, LDPE; PP; PS; and PET (Silvarrey \& Phan, 2016), PE (Borusiewicz \& Kowalski, 2016), coal and plastics blends ( Zhou, Luo, \& Huang, 2009), natural rubber (Al-hartomy et al., 2014), waste HDPE (Schwarzinger, Gabriel, Beimann, \& Buchberger, 2012), binary mixtures PP and LDPE (Chowlu, Reddy, \& Ghoshal, 2009), mixed between LDPE, HDPE, PP (Donaj, Kaminsky, Buzeto, \& Yang, 2012).

The catalyst in the pyrolysis of plastics serves to reduce reaction time and temperature, to optimize its kinetics and to enhance the quality of the product (Muqodam et al, 2015). The catalysts utilized in upgrading plastics are generally classified into a fluid cracking catalyst, reforming catalysts, and activated carbon (Kunwar, Cheng, Chandrashekaran, Sharma, 2016). Catalyst commonly used by many researchers include zeolites, cadmium, active matrix component, inactive matrix component, and binder (Roozbehani et al., 2017), silica-alumina (Moqadam et al., 2015), zeolite-based catalyst such as KBeta, HMOR, HZSM-5, HY, and KL zeolite (Levine \& Broadbelt, 2009; Muenpol, Yuwapornpanit, \& Jitkarnka, 2015), carbonsilica (Al-hartomy et al., 2014), zinc acetate ( Siddiqui, Redhwi, \& Achilias, 2012), natural zeolite without zeolite (Yuliansyah \& Laksono, 2015), triethylaluminum $\mathrm{Al}\left(\mathrm{C}_{2} \mathrm{H}_{5}\right)_{3}$ (Donaj et al., 2012), commercial $\mathrm{Y}$ zeolite and natural zeolite (Syamsiro et al., 2014), zeolite-based catalyst such as ZSM-5, BEA, US-Y, MOR (modified nanocrystalline $\mathrm{Y}$, amorphous silica-alumina (SAHA), silica-alumina and the family of mesoporous MCM material (Roozbehani et al., 2017). The aims of research are to investigate the influence of the rate of temperature and raw material to natural zeolite (wt\%) on gas, liquid, and solid yields in the pyrolysis of mixed between PP and HDPE and to identify the physical properties of fuel, namely its specific gravity, API gravity, gross heating value, flash point, pour point, and kinematic viscosity. 


\section{EXPERIMENTAL SECTION}

Plastic bottles considered as polypropylene (PP) and waste caps considered as highdensity polyethylene (HDPE) were used in the research. Raw materials were bought from waste collectors at the Tirtonadi Bus Station, Surakarta, Central Java, Indonesia. Natural zeolite as a catalyst was bought from Bratachem. The pyrolysis equipment consisted of a reactor with a capacity of two kilograms, diameter of $25 \mathrm{~cm}$ and height of $40 \mathrm{~cm}$, a condenser, two thermocouples, two liquid storages, a manometer, and three gas storages. Liquid petroleum gas was used for the combustion process. Two thermocouples were installed to monitor the process, one in the pyrolytic chamber (reactor) and the other at the exit line of the condenser. The raw material was cleaned and then cut into approximately uniform sizes of $3 \times 3 \mathrm{~cm}$. Approximately 800 grams of plastic bottles and 200 grams of cap waste were put into the reactor which was connected to a thermocouple to control the temperature operation. The pipe at the top of the reactor was connected to the cyclone which separates gas from solid. Gas produced by the reaction was condensed using the first condenser, resulting in a liquid product that was then collected. Part of the produced gas which was not condensed was condensed again in the second condenser and the yield was then stored in three gallons. The gas volume was calculated based on the volume of water flowing from the gallon. the operation was repeated with various ratios of plastics to natural zeolite, 67:33 wt\%; 75:25 wt \%; 80:20 $\mathrm{wt} \%$; and 83:17 wt $\%$. Pyrolysis was performed for two hours, and every 20 minutes a sample was weighed to measure the mass changes of the gas and liquid. After 120 minutes, a solid sample was examined to determine the mass of the final solid. The other properties were analyzed with the ASTM method (Syamsiro et al., 2014) as shown in Table 1. The liquid product was analyzed in Petroleum, Gas, and Coal Laboratory, Chemical Engineering Department, Universitas Gadjah Mada, Yogyakarta, Indonesia. The caps as sources of HDPE waste and plastic bottles as a source of $\mathrm{PP}$ are presented in Figure 1(a) and Figure 1(b).

Table 1. Analysis of Liquid with Variations in Temperature and Weight Percentage of Raw Material to Natural Zeolite

\begin{tabular}{|c|c|c|c|c|c|c|}
\hline No. & Characteristics & Unity & $\begin{array}{l}\text { Indonesian } \\
\text { National } \\
\text { Standard } \\
\end{array}$ & $\begin{array}{l}\text { Temperature } \\
\text { Variation }\end{array}$ & $\begin{array}{l}\text { Zeolite } \\
\text { Composition } \\
\text { Variation } \\
\end{array}$ & $\begin{array}{l}\text { (Syamsiro } \\
\text { et al., } 2014\end{array}$ \\
\hline 1. & $\begin{array}{l}\text { Specific Gravity at } \\
60 / 60 \mathrm{~F}\end{array}$ & - & 0.742 & 0.7752 & 0.7765 & 0.77 \\
\hline 2. & API Gravity & - & - & 51.0 & 50.7 & \\
\hline 3. & $\begin{array}{l}\text { Gross Heating } \\
\text { Value }\end{array}$ & $\mathrm{MJ} / \mathrm{kg}$ & $\geq 41.87$ & 46.59 & 46.403 & 20.091 \\
\hline 4. & Flash Point PM c.c & ${ }^{\circ} \mathrm{C}$ & $\min 60$ & $<20$ & $<20$ & 10 \\
\hline 5. & Pour Point & ${ }^{\circ} \mathrm{C}$ & Maks 18 & -12 & -6 & \\
\hline 6. & $\begin{array}{l}\text { Kinematic } \\
\text { Viscosity at } 40^{\circ} \mathrm{C}\end{array}$ & $\mathrm{mm}^{2} / \mathrm{s}$ & $2.0-5.0$ & 1.426 & 1.410 & 1.4 \\
\hline
\end{tabular}
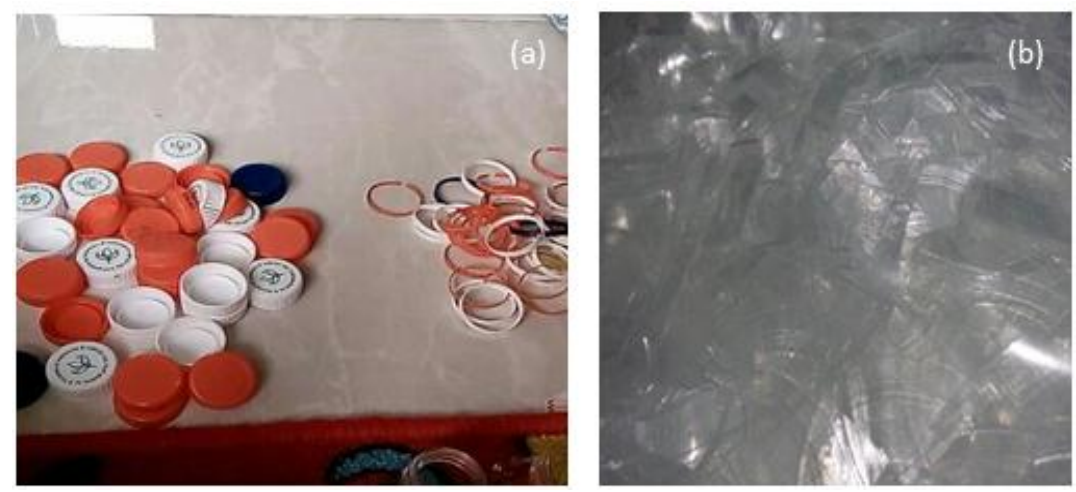

Fiqure 1. Caps as the source of HDPE waste (a) and plastic bottles as source of PP waste (b) 


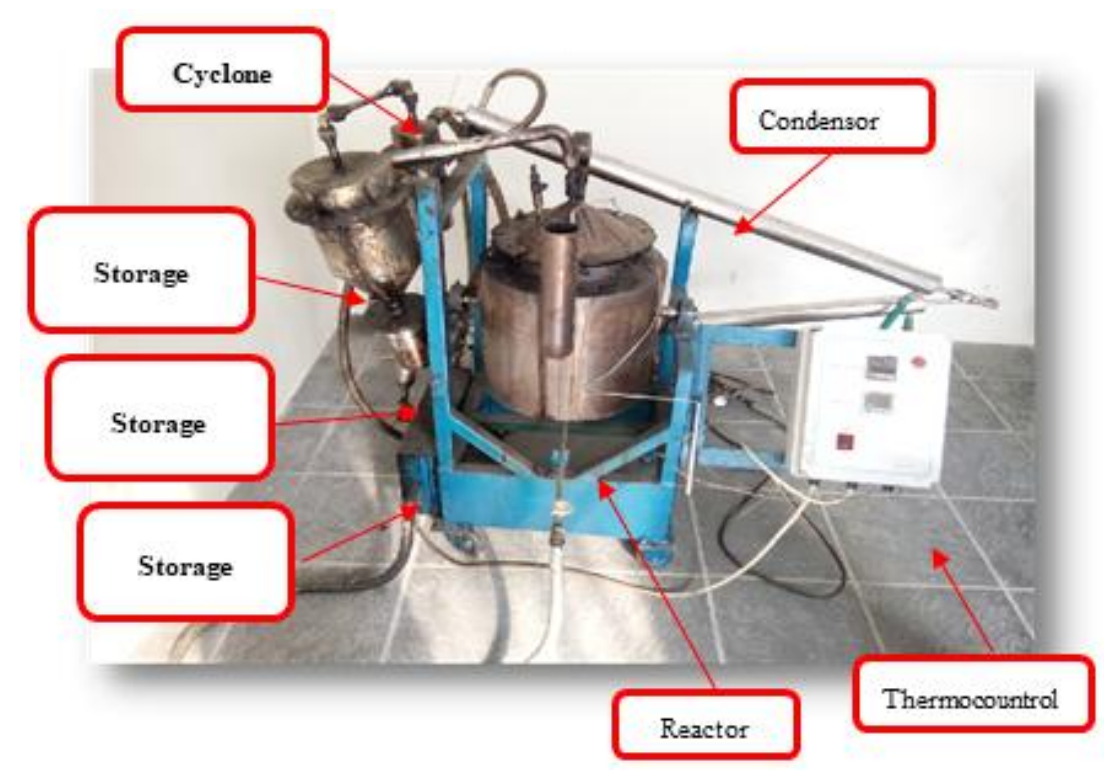

Figure 2. Pyrolysis Equipment

\section{RESULTS AND DISCUSSION}

As shown in Figure 3, the graph gives information about the relationship between liquid mass and temperature variation. At temperature $410{ }^{\circ} \mathrm{C}$ from beginning the starting condition to the first twenty minutes, the mass degraded very slowly. After twenty minutes, degradation rapidly increased. It is interesting to note that after two hours the total liquid mass was relatively stable at approximately 500 grams. On the other hand, in varied catalyst rates there was no liquid from the initial condition until the first twenty minutes, but after one hour the decomposition of liquid advanced much faster.

The changes in gas volume over time and the percentage of raw material and catalyst are shown in Figure 4(a) and (b). The production of gas started after a third of an hour. The total volume of gas at three temperatures variants $\left(410,420\right.$ and $\left.430{ }^{\circ} \mathrm{C}\right)$ was twice higher than at $440^{\circ} \mathrm{C}$. Meanwhile, from the four variations of rates of plastics to natural zeolite catalyst (66: $33 \mathrm{wt} \% ; 75: 25$ wt \%; 80: $20 \mathrm{wt} \%$, and 83: $17 \mathrm{wt} \%)$ as in Figure 3(b). the volume of gas in the weight percentage ratio of plastic waste to the catalyst at 83:17 was the lowest.

Figure 5a and $\mathbf{5 b}$ illustrate changes of solid residue over time based on temperature and percentage of raw material. The graphs in Figure 5a describe mass changing of solid residue at different temperatures. Liquid, gas, and solid yields in different temperatures and the weight percentage of raw material to catalyst is shown in Figure 6 and Figure 7.

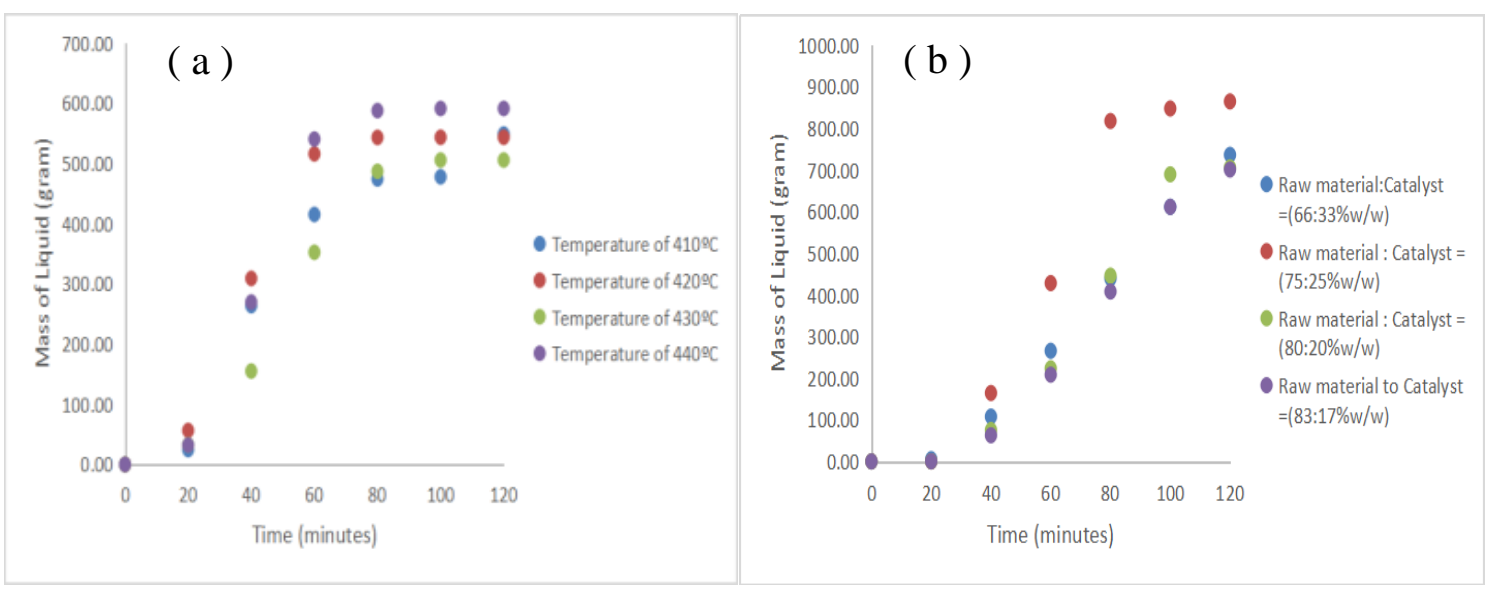

Figure 3. Change of oil pyrolysis profile (grams) over time (minutes) with variation in (a) temperature and (b) percentage ratio of raw material to catalyst 


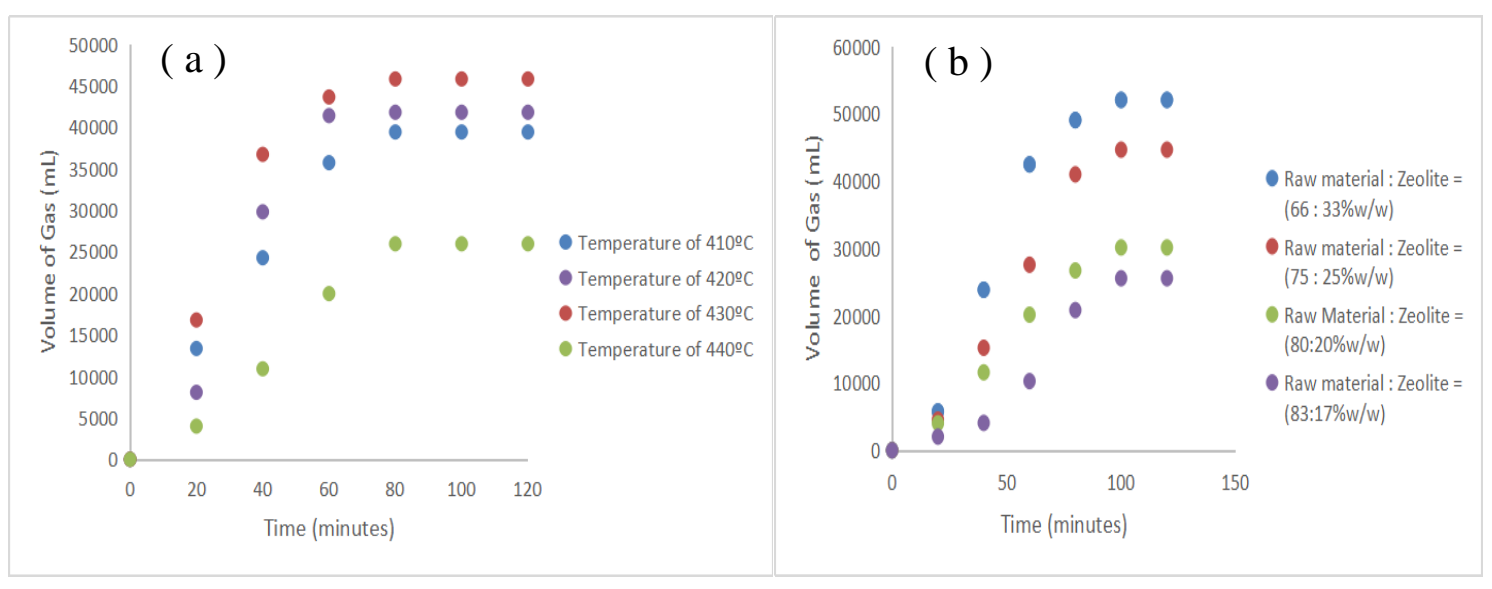

Figure 4. Change of gas volume profile $(\mathrm{mL})$ over time (minutes) with variation in (a) temperature, and (b) percentage ratio raw material to catalyst

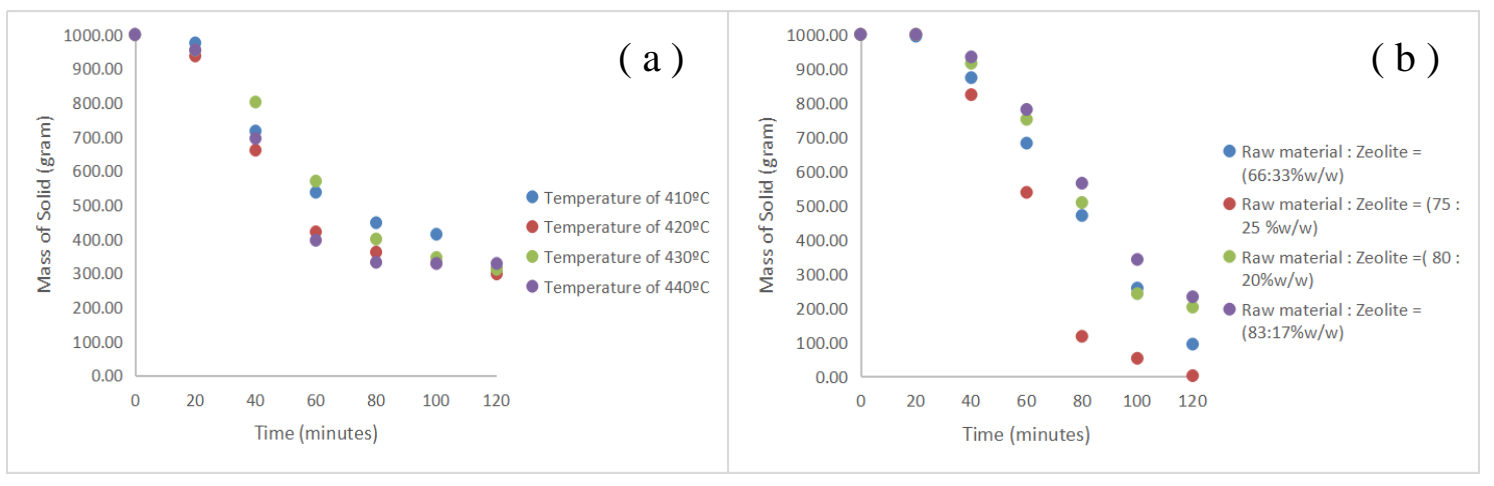

Figure 5. Mass change of solid residue (grams) over time (minutes) with variation in (a) temperature and (b) weight percentage of raw material to the catalyst

The vertical bar chart describes the relationship between the yields of liquid, gas, and solid and temperature variations. There are four temperature variations namely 410 , 420,430 and $440{ }^{\circ} \mathrm{C}$. The most distinguishing feature is at $440{ }^{\circ} \mathrm{C}$ where the liquid yield was highest at $68.42 \%$. On the other hand, the proportions of liquid yield in temperature variations of 410,420 and $430^{\circ} \mathrm{C}$ were $54.86 \%, 62.12 \%$, and $56.38 \%$ respectively. These results corroborate those of other research (Aboulkas et al., 2010; Moqadam et al., 2015) in which thermal and catalytic degradation polystyrene mainly produces liquid.

According to a study on mixed plastic waste composed of $75 \%$ of polyolefins and $25 \%$ PS (Kaminsky, Schlesselmann, \& Simon, 1996) the product comprised 46.6 wt $\%$ liquid, $35 \mathrm{wt} \%$ gas, and $2.2 \mathrm{wt} \%$ solid. Another study (Paradela, Pinto, Gulyurtlu, Cabrita, \& Lapa, 2009), used a mixture of HDPE, LDPE, PP, PS, PVC, PET with the concentration of liquid, solid, gas, wax, were
$40,30,15,10,3$ and $2 \mathrm{wt} \%$ respectively. Its results showed that the liquid obtained was higher at the lower temperature of $650^{\circ} \mathrm{C}$ which was around the $48 \mathrm{wt} \%$. However, the oil fraction consisted of $52 \%$ heavy fraction such as heavy oil, wax, and carbon black. In contrast, it is was up.

It is interesting to note that in the temperature variation of 410 and $430^{\circ} \mathrm{C}$ the gas yield was relatively the same at approximately $40 \%$. Meanwhile, at $440^{\circ} \mathrm{C}$ yield gas was less than at the other three variations. The gases resulting from pyrolysis of mixed (PP) and (LDPE) are $\mathrm{C}_{6}, \mathrm{C}_{6}-\mathrm{C}_{10}, \mathrm{C}_{11^{-}}$ $\mathrm{C}_{13}$, and $>\mathrm{C}_{13}$. The highest gas yield with the variation of PP $(80 \%)+\mathrm{LDPE}(20 \%)$ at $11.17 \%$ was lower than the yield of mixed PP and HDPE. The vertical bar chat illustrates the relationship of the composition of zeolite and raw material with liquid, gas, and solid yields. There are four variations given in the comparison of raw material to natural zeolite (66:33 wt\%; 75:25 wt\%, 80:20 wt\%, and $83: 17 \mathrm{wt} \% \mathrm{w})$. 


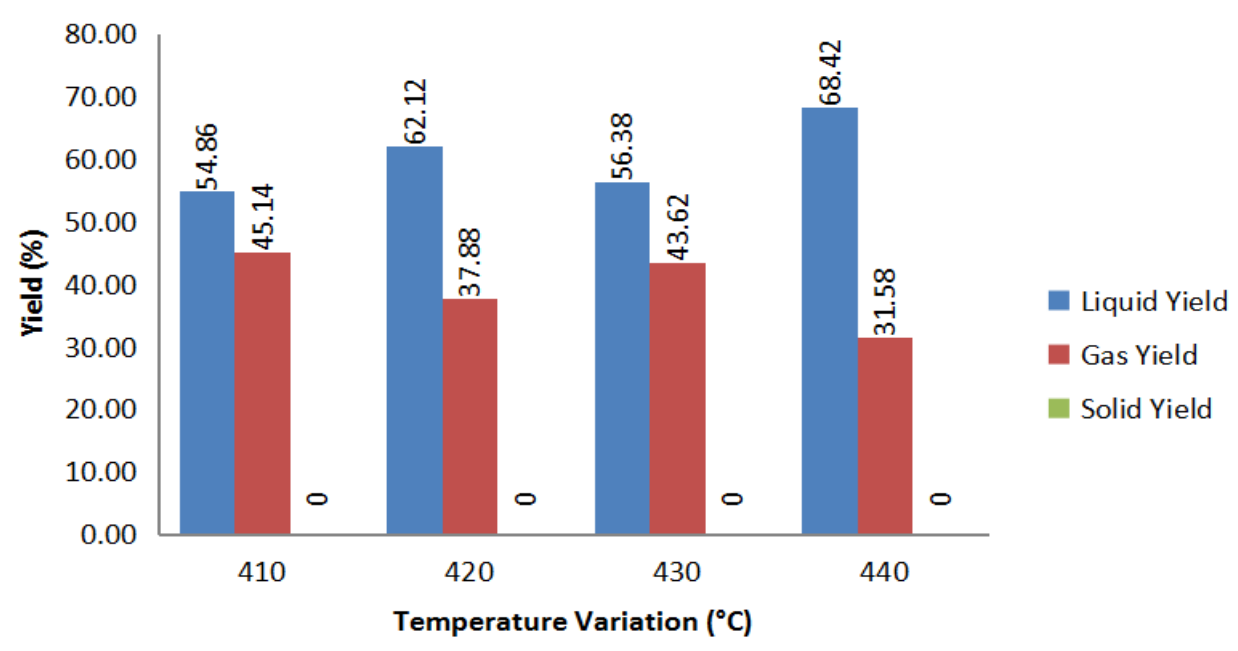

Figure 6. The relationship between Temperature Variation and Yield

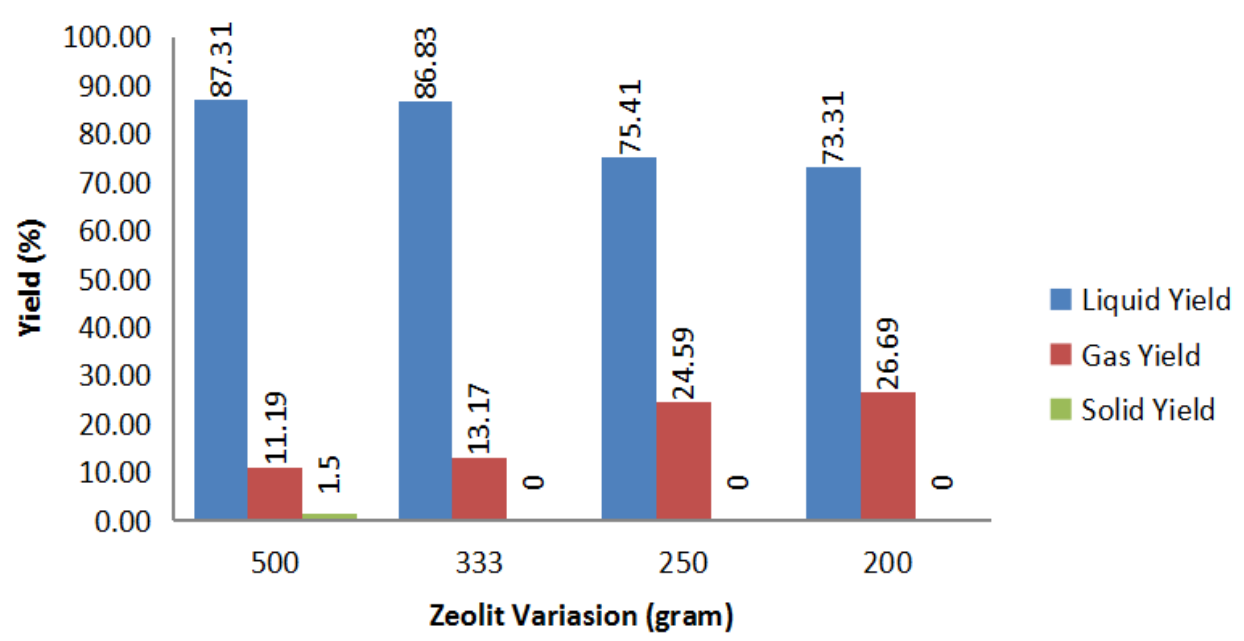

Figure 7. The relationship between the variation of mass of catalyst and yield

The most striking feature is that the higher the rate of zeolite to raw material, the greater liquid yield. It can be seen that at a rate of raw material to the natural zeolite of 80:20 $\mathrm{wt} \%$ the gas yield was two times that at 75:25 wt $\%$. It is also noticeable that gas yield at 66:33 wt $\%$ variation was half that at 83:17 wt\%. On the other hand, according to variations in the ratio of raw material to zeolite, the largest liquid yield was $87.31 \%$. The percentages of liquid yield at the other three variants were $86.83,75.41$, and $73.31 \%$ in that order. In contrast, in the pyrolysis of polystyrene, when the mass of catalyst has increased the yield of liquid is reduced (AlSalem \& Lettieri, 2010). It is interesting to note that in these variations there was no solid residue resulting from this process.

Liquid product from various temperatures and natural zeolite compositions were analyzed in Petroleum, Gas, and Coal
Laboratory, Chemical Engineering Department, Universitas Gadjah Mada, Indonesia. The liquid analysis result can be seen in Table 1. Table 1 shows that according to data analysis the liquid product is suitable solar (diesel) fuel based on Decree of The Director General of Oil and Gas Year for 2,008 Number 14,496 K/14/DJM/2,008, Ministry of Energy and Mineral Resources of the Republic Indonesia, concerning the Standards and Quality (Specifications) of Oil Fuels of the Combustible Oil Variety Traded in Indonesia. Likewise, the research found that the proportion of liquid plastic produced by pyrolysis of $100 \%$ plastic provided a GHV of $44.7 \mathrm{MJ} / \mathrm{kg}$ (Paradela et al., 2009). The liquid products were found to be similarities to diesel fuel in the value of, specific gravity, gross heating value, pour point, and kinematic viscosity. 


\section{CONCLUSIONS}

From the research, the followings can be concluded.

1. The temperature of $440^{\circ} \mathrm{C}$ produced the highest liquid yield at $68.42 \%$ and highest gas yield was $45.14 \%$ at $410^{\circ} \mathrm{C}$, while there was no solid residue at any temperature variation

2. The ratio of plastics raw material to the catalyst of 66:33 wt $\%$ provided the highest liquid and solid yields at $87.13 \%$ and $26.69 \%$, respectively

3. The liquid product was found to be suitable as a diesel fuel base on Decree of the Director General of Oil and Gas Year 2008.

\section{ACKNEWLEDGEMENTS}

The authors would like to express their utmost gratitude for financial sponsorship of Ministry of Research, Technology, and Higher Education of the Republic Indonesia through The Applied Product Grand Scheme, Contract Number: 211.27/A.3-III/LPPM/V/2017.

\section{REFERENCES}

Aboulkas, A., El harfi, K., \& El Bouadili, A. (2010). Thermal degradation behaviors of polyethylene and polypropylene. Part I: Pyrolysis kinetics and mechanisms. Energy Convers. Manag., 51, 13631369.

Aboulkas, A., El harfi, K., El bouadili, A., Nadifiyine, M., Benchanaa, M., \& Mokhlisse, A. (2009). Pyrolysis kinetics of olive residue/plastic mixtures by nonisothermal thermogravimetry. Fuel Process. Technol, 90, 722-728.

Åkesson, D., Krishnamoorthi, R., Foltynowicz, Z., Christéen, J., Kalantar, A., \& Skrifvars, M. (2013). Glass Fibres Recovered by Microwave Pyrolysis as a Reinforcement for Polypropylene. Polymers and Polymers Composite, 21, 333-340.

Al-hartomy, O.A., Al-ghamdi, A.A., Farha, S.A., Said, A., Dishovsky, N., Mihaylov, M., Ivanov, M., \& Ljutzkanov, L. (2014). Effect of the Carbon-Silica Reinforcing Filler Obtained from the Pyrolysis-cum-Water Vapour of Waste Green Tyres upon the Properties of Natural Rubber Based Composites. Progress in Rubber,
Plastics, and Recycling Technology.31, 25-42.

Al-Salem, S.M., \& Lettieri, P. (2010). Kinetic study of high density polyethylene (HDPE) pyrolysis. Chem. Eng. Res. Des., 88, 1599-1606.

Borusiewicz, R., \& Kowalski, R. (2016). Volatile organic compounds in polyethylene bags-A forensic perspective. Forensic Sci. Int., 266, 462-468.

Chen, X., Wu, H., Luo, Z., Yang, B, Guo, S, \& $\mathrm{Yu}$, J. (2007). Synergistic Effects of Expandable Graphite With magnesium Hydroxide on the Flame Retardancy and Thermal Properties of Polypropylene, Polymer Engineering and Science, 47, $11,1756-1760$

Chin, B.L.F., Yusup, S., Al Shoaibi, A., Kannan, P., Srinivasakannan, C., \& Sulaiman, S.A., (2014). Kinetic studies of co-pyrolysis of rubber seed shell with high density polyethylene. Energy Convers. Manag., 87, 746-753.

Chowlu, A.C.K., Reddy, P.K., \& Ghoshal, A.K. (2009). Pyrolytic decomposition and model-free kinetics analysis of mixture of polypropylene (PP) and lowdensity polyethylene (LDPE). Thermochim. Acta 485, 20-25.

Donaj, P.J., Kaminsky, W., Buzeto, F., \& Yang, W. (2012). Pyrolysis of polyolefins for increasing the yield of monomers' recovery. Waste Manag., $32,840-846$.

Gogotov, I.N., \& Barazov, S.K. (2014). The effect of ultraviolet light and temperature on the degradation of composite polypropylene. Int. Polym. Sci. Technol. 41, 55-58.

Moqadam, S.I, Mirdrikvand, M., Roozbehani, B., Kharaghani, A., \& Shishehsaz, M.R. (2015). Polystyrene pyrolysis using silica-alumina catalyst in fluidized bed reactor. Clean Technol. Environ. Policy 17, 1847-1860.

Kaminsky, W., Schlesselmann, B., \& Simon, C.M. (1996). Thermal degradation of mixed plastic waste to aromatics and gas. Polym. Degrad. Stab. 53, 189-197.

Kumar, S., \& Singh, R. K. (2014). Pyrolysis Kinetics of Waste High-density Polyethylene using Thermogravimetric Analysis Pyrolysis Kinetics of Waste 
High-density Polyethylene using. Int. J. ChemTech Res., 6, 131-137.

Kumar, S., \& Singh, R.K. (2011). Recovery of hydrocarbon liquid from waste high density polyethylene by thermal pyrolysis. Brazilian J. Chem. Eng., 28, 659-667.

Kunwar, B., \& Cheng, H.N., Chandrashekaran, S.R., Sharma, B.K. (2016). Plastics to fuel: a review. Renew. Sustain. Energy Rev., 54, 421428.

Levine, S.E., \& Broadbelt, L.J. (2009). Detailed mechanistic modeling of highdensity polyethylene pyrolysis: Low molecular weight product evolution. Polym.Degrad. Stab., 94, 810-822.

Mastellone, M.L., \& Arena, U. (2002). Fluidized-bed pyrolysis of polyolefins wastes: Predictive defluidization model. AIChE J., 48, 1439-1447.

Muenpol, S., Yuwapornpanit, R., \& Jitkarnka, S. (2015). Valuable petrochemicals, petroleum fractions, and sulfur compounds in oils derived from waste tyre pyrolysis using five commercial zeolites as catalysts: Impact of zeolite properties. Clean Technol. Environ. Policy, 17, 1149-1159.

Paradela, F., Pinto, F., Gulyurtlu, I., Cabrita, I., \& Lapa, N. (2009). Study of the copyrolysis of biomass and plastic wastes. Clean Technol. Environ. Policy 11, 115-122.

Roozbehani, B., Motevassel, M., Mirdrikvand, M., Moqadam, S.I., \& Kharaghani, A. (2017). Gasoline production from a polymeric urban disposal mixture using silica-alumina catalyst. Clean Technol. Environ. Policy, 19, 123-136.

Roozbehani, B., Sakaki, S.A., Shishesaz, M., Abdollahkhani, N., \& Hamedifar, S. (2015). Taguchi method approach on catalytic degradation of polyethylene and polypropylene into gasoline. Clean
Technol. Environ. Policy, 17, 18731882.

Sakaki, S.A., Roozbehani, B., Shishesaz, M., \& Abdollahkhani, N. (2014). Catalytic degradation of the mixed polyethylene and polypropylene into middle distillate products. Clean Technol. Environ. Policy, 16, 901-910.

Schwarzinger, C., Gabriel, S., Beimann, S., \& Buchberger, W. (2012). Quantitative analysis of polymer additives with MALDI-TOF MS using an internal standard approach. J. Am. Soc. Mass Spectrom., 23, 1120-1125.

Sharuddin, S.D.A., Abnisa, F., Daud, W.M.A.W., \& Aroua, M.K. (2016). A review on pyrolysis of plastic wastes. Energy Convers. Manag., 115, 308-326.

Siddiqui, M.N., Redhwi, H.H., \& Achilias, D.S. (2012). Recycling of poly(ethylene terephthalate) waste through methanolic pyrolysis in a microwave reactor. $J$. Anal. Appl. Pyrolysis, 98, 214-220.

Silvarrey, L.S.D., \& Phan, A.N. (2016). Kinetic study of municipal plastic waste. Int. J. Hydrogen Energy 41, 16352-16364.

Syamsiro, M., Saptoadi, H., Norsujianto, T., Noviasri, P., Cheng, S., Alimuddin, Z., \& Yoshikawa, K. (2014). Fuel oil production from municipal plastic wastes in sequential pyrolysis and catalytic reforming reactors. Energy Procedia, 47, 180-188.

Yuliansyah, A.T., Prasetya, A., Ramadhan, M.A.A. \& Laksono, R. (2015), Pyrolysis of Plastics Waste to Produce Pyrolytic Oil As An Alternative Fuel. International Journal of Technology, 7, 1076-1083

Zhou, L., Luo, T., \& Huang, Q. (2009). Copyrolysis characteristics and kinetics of coal and plastic blends. Energy Convers. Manag. 50, 705-710. 